\title{
LA "PIEDRA ESCRITA" DE DIANA, EN CENICIENTOS (MADRID), Y LA FRONTERA ORIENTAL DE LUSITANIA
}

\author{
Alicia M. ${ }^{a}$ CANTO \\ Universidad Autónoma de Madrid
}

\section{Resumen}

En este artículo se reestudia un monolito de granito con algunos relieves y un epígrafe romano, retocado en época moderna. Podría tratarse de un pequeño oratorio a Diana, parecido a su santuario rupestre de Segóbriga (Cuenca). Se propone también una relación de este monumento con los -Toros de Guisando- (prov. de Ávila) y otros -verracos, esculpidos o no, hacia el Sur (prov. de Toledo), sugiriendo una hipótesis sobre este tramo de la frontera oriental de la provincia de Lusitania: En esta línea podría insertarse -Piedra Escrita.

\section{Summary}

This paper deals with the study of a granite monolith with some reliefs and a latin inscription that was retouched in modern times. It could be a small aedicula consecrated to the goddess Diana, similar to her rock shrine in Segobriga. It is also proposed a possible link between this monolith, the -Toros de Guisando- (prov. of Avila) and other -verracos, sculpted or not, towards the south (prov. of Toledo), suggesting an hypothesis about this eastern border of the roman Lusitania: On this line could be inserted -Piedra Escrita.

\section{PUBLICACIONES ANTERIORES}

Se trata del monumento conocido como "Piedra Escrita", ubicado en zona rural del término de Cenicientos (Madrid). Fue recogido en la Carta Arqueológica de la Provincia de Madrid $^{1}$, y publicado por primera vez cuatro años más tarde por J. Mangas, S. Ripoll y J.J. Storch

${ }^{1}$ Un equipo, dirigido por L. Caballero, realizó en 1984 las fichas de la provincia de Madrid para la Consejería de Urbanismo de la C.A.M. En ella y en el Museo Arqueológico Nacional pueden consultarse las mismas, puesto que, como tal carta arqueológica, no ha sido objeto de publicación. En 1995 se estaban llevando a cabo algunos trabajos de actualización de esta Carta. 
de Gracia (1988, 58-59, con foto). Ambas referencias sirvieron de base a la mención del monumento dada por la TIR $(1993,178)$, donde, sin embargo, no se recoge el estudio anterior de R.C. Knapp (1992, 195-196, n. ${ }^{\circ} 221$, con dibujo). En último lugar, a raíz de varias informaciones de prensa, que incluyeron declaraciones en torno al monumento de las autoridades locales y de los arqueólogos F. Velasco y A. Fuentes (-El País", Madrid, 12 y 14 de Octubre de 1995), se hicieron, a cargo de la Comunidad de Madrid (que fue requerida para ello por el Excmo. Ayuntamiento de Cenicientos) varias catas a su alrededor, cuyos resultados, ciertamente inconcluyentes, publicaron los arqueólogos J.L. Morón y J.L. Martín Mompeán (1995, 20-22, con fotos ${ }^{2}$ ).

Después de todo ello, sin embargo, la definición del monumento mismo, de sus relieves delanteros, de su labrada zona trasera, así como de la inscripción que la aclara, pero que presenta indudables problemas de lectura, sigue siendo, en palabras del alcalde de la localidad un misterio"; en las de uno de los arqueólogos citados, "un bello enigma", mientras que los autores de los cuatro sondeos arqueológicos concluyen, sorprendentemente, que -los materiales cerámicos encontrados en la excavación no han posibilitado la determinación exacta de la época cultural a la que pertenece el presente yacimiento (monumento y entorno cercano), aunque abunda la cerámica de época romana (sigillata) ${ }^{3}$.

Por otra parte, son muy divergentes (y a veces disparatadas) las interpretaciones funcionales del monumento (hasta llegar a pensar que la gran peña es el único "muro interior" que subsiste en pie de un templo, o que por su escalera" posterior se subía a hacer sacrificios en lo alto), así como las de los cuatro orificios que presenta en su cara principal, por lo que no me detengo en ellas. En cuanto al epígrafe, el único en ofrecer una lectura fue R.C. Knapp, que lo entendió como muestra de la "cristianización post-clásica", en un lugar convertido en objeto de peregrinación medieval, de los relieves de un monumento romano con ninfas (para él las tres figuras van vestidas con ropa femenina), quizá del siglo II d.C. Las figuras recordarían a los peregrinos del Medioevo a las tres homónimas del Nuevo Testamento, y grabaron, en letras para él "poorly cut": "A las tres/Marias". Pensó Knapp que el verdadero epígrafe romano estuvo en el espacio inferior de la roca, donde Mangas et al. habían visto un toro y otra figura animal no identificada, y Knapp el espacio epigráfico raspado ${ }^{4}$.

\section{LA UBICACIÓN}

Atraída especialmente por la bella rusticidad de este que, al margen de la clasificación arqueológica, puede con justicia llamarse "megalito", lo visité el 19 de Noviembre y

${ }^{2}$ Toda la descripción del monumento (pág. 20) que, antes de informar sobre sus excavaciones, ofrecen estos jóvenes autores es copia literal del artículo de J. Mangas et al. de 1988, a los que además no citan. Ello es más de lamentar cuando se lleva en la cabecera de la publicación el anagrama de la -Comisión de Arqueólogos Profesionales;, y se trabaja de forma oficial, en nombre de la Comunidad Autónoma de Madrid.

${ }^{3}$ Cf. sobre ello -El País, Madrid, 19-12-1995 y, posteriormente, las ediciones de 22-12-1995 y 7-1-1996.

4 Aclara que J. Zozaya le transmitió la información de un granjero vecino, según el cual el propietario, hacía unos años, había martilleado la inscripción que allí había. Sin embargo, el lugar es inapropiado y, en el cuadro inferior del relieve no hay resto alguno de haber contenido inscripción. 
el 23 de Diciembre de 1995. Se alza en una suave altura, en el interior de un vinedo salpicado de encinas jóvenes y varios olivos, que ocupan zona algo más elevada. Está a unos $4 \mathrm{Km}$. al SO. de Cenicientos, que es a su vez el último municipio al SO. de la provincia de Madrid, y casi en el linde de la provincia de Toledo (fig. 1). Hay que desviarse de la carretera de Cenicientos (M.) a Almorox (TO.), a la altura de un improvisado vertedero moderno, y continuar por una vereda hasta un amplio llano, donde termina el carril. Sus coordenadas son $40^{\circ} 14^{\prime} \mathrm{N}$. y $4^{\circ} 26^{\prime} \mathrm{O}$. (TTR, ibid.), y no está próximo a ninguna vía de comunicación ni núcleo urbano antiguos conocidos.

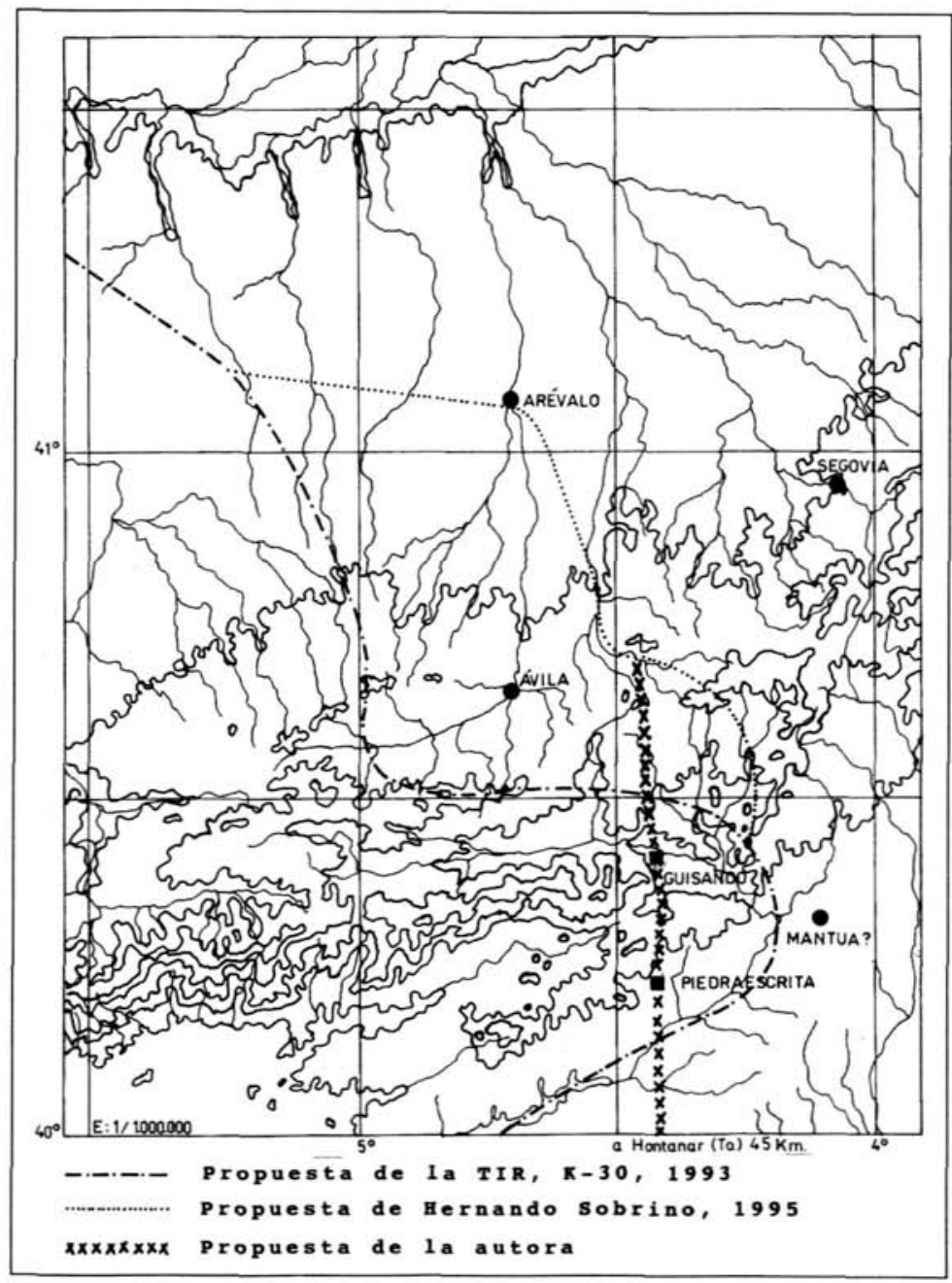

Figura 1. Ubicación de Piedra Escrita y su posible alineación con los Toros de Guisando (AV.) y Hontanar (TO.). Propuesta para la división entre Lusitania y Citerior Tarraconense (a partir del mapa de la TIR, E:1.000.000). Zona Norte 
Según la TIR (mapa), sería el último monumento o resto antiguo del territorio vetón y del convento emeritense, cuya divisoria pasaría unos kilómetros más al $\mathrm{E}$. de él. Con esta frontera teórica (que hasta ahora sólo parece apoyarse en la actual deslinde entre las provincias de Madrid y Toledo) concordaría la tesis de A. Fuentes ("El País", 14-10-1995) de que el monumento estaría en la divisoria entre dos conventus ${ }^{5}$. Aunque, como veremos más abajo, el enclave de "Piedra Escrita", junto con otros dos que mencionaré, ayudaría más bien a situar el límite exactamente por este lugar, en línea recta N.-S., y por tanto más al Oeste de lo propuesto por el mapa de la TIR. Se sitúa en el valle del río Alberche, al S. de las estribaciones más occidentales de los Montes de Toledo; en el paso entre las zonas más montañosas de las sierras de Guadarrama y Gredos, y las llanuras toledanas. El paisaje es, pues, plenamente fronterizo.

\section{EL MONUMENTO Y LOS RELIEVES}

Se trata, en efecto, de una gran piedra natural de granito, aparentemente in situ y por arriba de forma aproximadamente trapezoidal, de unos $5 \mathrm{~m}$. de altura por casi 4 de ancho (lám. 1 a). En la parte central de su cara norte (en realidad orientada E.-NE.), se labró una hornacina vertical, rehundida entre 16 y $20 \mathrm{~cm}$., de unos $2.40 \mathrm{~m}$. de alto ${ }^{6}$ por 1.27 de ancho, con tres espacios bien delimitados: Una cabecera semicircular en forma de concha lisa (más superficial) y dos espacios rectangulares apaisados, que miden en conjunto $1.77 \times 1.27 \mathrm{~m}$.

En el central se desarrolla el relieve principal (láms. 1 b y 2a): A ambos lados de un ara (quizá trípode para Knapp), definida por bajorrelieve, se disponen tres figuras en relieve. La de la izquierda del ara, vestida con ropas femeninas, tiene mayor volumen y prestancia que las otras dos, hacia las que ella mira. Parece llevar cubierta la cabeza por un velo y sujeta en su mano izquierda un urceus, como derramando líquido sobre una pátera, sostenida por la figura que vemos a su derecha. Aún me parece posible distinguir otro objeto, rígido, que sostiene horizontalmente en su mano derecha, por delante del manto, de forma aproximadamente ovalada y compuesto de muchas borlas o cuentas.

Las otras figuras están en el lado derecho del ara. De estas dos, la de nuestra diestra es sin duda un varón togado, que, más que pasar su brazo derecho por el hombro de la figura central, está simplemente junto a ella, mientras con el izquierdo parece asirla por un brazo. En torno a su antebrazo y mano pende un objeto de extraña forma y borde inferior dentado, que quizá sea un sistro. La figura central, de ropaje mujeril, que semeja llevar también velo, alarga a su vez el brazo derecho hacia el altar, pareciendo sujetar, como dije, la pátera (parte de la cual se oculta tras el jarrito). En conjunto, parecen un matrimonio que realiza un sacrificio en un altar y ante una diosa, que atiende a su ofrenda y ofrece a su vez una libación ${ }^{7}$.

\footnotetext{
5 Para él las figuras (dos) serían las de un sacerdote y una divinidad, como símbolo -del culto al emperador y el reparto de justicia- (scil., en relación con los conventos).

6 La altura total es relativa, por la dificultad de medios para medirla con precisión.
} 
El relieve inferior presenta claras señales de haber sido picado recientemente (al menos antes de 1983: Knapp, loc.cit.) en casi toda su superficie, que ahora ofrece un aspecto blanquecino. Mirado desde varios puntos, parecen poder distinguirse aún, a la derecha, la figura de una vaca o buey, echada en el suelo, ocupando toda la altura del recuadro y con la cabeza echada ligeramente como hacia atrás. En el lado izquierdo, y con línea de suelo exactamente a la mitad de la altura, se distingue mucho mejor una pequeña ternera o, mejor, una cabra, de frente, con cuernecillos rectos. Puestos en relación lógica con el relieve superior, podrían ser o bien los animales ofrendados en el sacrificio arriba descrito, o bien animales representativos de la divinidad, o ambas cosas.

Ofrezco (fig. 2) una interpretación de lo observado, utilizando la mediación de un scanner, retocado para reforzar los detalles ${ }^{8}$.

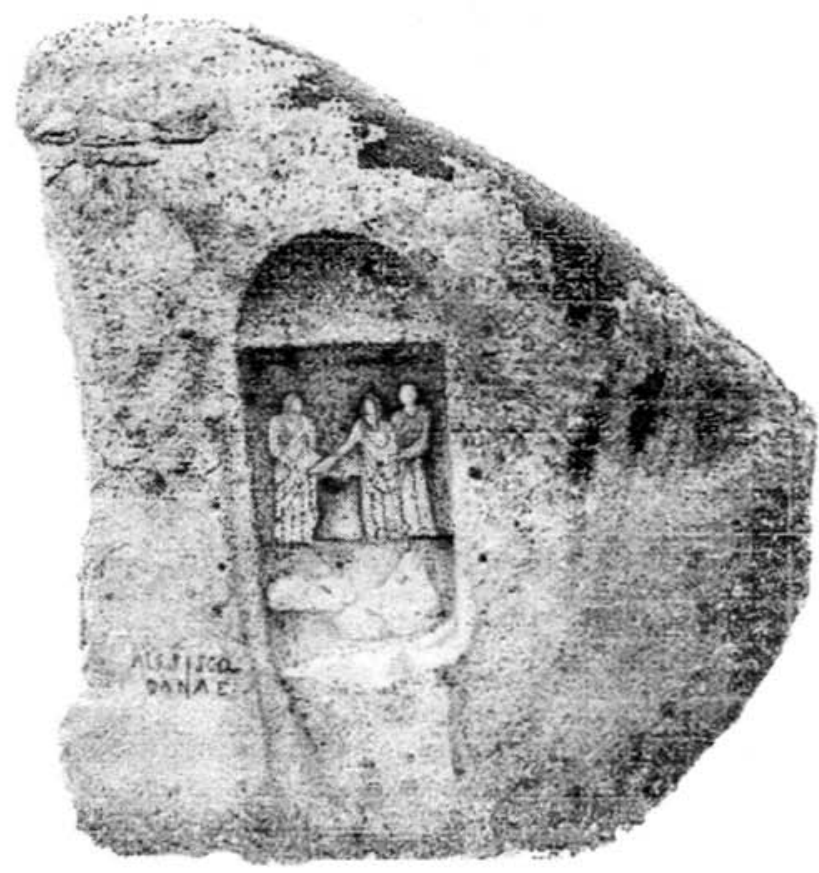

Figura 2. Reconstrucción hipotética del monumento de Piedra Escrita. Según S. Luzón, A. Rubio y A. Canto

${ }^{7}$ Debo aclarar que, dado el malísimo estado de conservación de los relieves, mi propia descripción queda abierta a otras interpretaciones. Trato en principio de establecer por vez primera el tema que se nos presenta. Cahe, por ejemplo, pensar en una sacerdotisa de la diosa, puesto que liba. Pero su gesto, entre digno y altivo, es lo que me lleva a pensar que, aunque más extraño, pueda ser la misma diosa.

8 Agradezco a los estudiantes de Arquitectura Sara Luzón Canto y Antonio Rubio Valenzuela su amabilidad y paciencia al realizar esta ilustración interpretada, donde se han remarcado los detalles que he observado en las fotografías con ayuda de un cuentahilos. 


\section{LAS OQUEDADES}

A los dos lados de la hornacina se observan dos pares de oquedades (lám. 1b) no muy profundas, que no se entienden a través de ninguna de las explicaciones que se han dado? ${ }^{9}$ Me parece importante para averiguar su función observar, lo que no se ha hecho, que el conjunto de la roca presenta dos tonos claramente diferenciados, y que esta diferenciación se produce exactamente a la altura de las citadas oquedades. El detalle es perceptible in situ y en las fotografias en color $^{10}$. La parte superior tiene la pátina propia del granito expuesto desde siempre a la intemperie: Grises salpicados de manchas verdosas de musgo y más oscuras de la superficie transformada. En cambio la zona inferior, desde la mitad de la hornacina aproximadamente (donde están justamente los agujeros), parece haber estado mucho menos tiempo expuesta, y haber sido objeto de roces frecuentes, por lo que presenta un color rojizo y una superficie más alisada.

Creo, en fin, que se puede deducir de este detalle que algún tipo de tejadillo se adosó, en época mucho más reciente, a esta pared, y que en el improvisado y rudo habitáculo se vivió e hizo fuego durante bastante tiempo, explicando así los roces en la piedra y la distinta coloración. Y también puede decirse que dichos ocupantes no tuvieron relación alguna, ni religiosa ni respetuosa, hacia el monumento, puesto que la mitad superior de la homacina la dejaron expuesta al aire. Esto me parece suficiente para desligar funcionalmente las oquedades del monumento mismo. Y, en efecto, observando, en el área próxima, un refugio de pastores muy toscamente construído, con materiales de desecho, puede hacerse uno idea de cómo se practicaron los poco profundos agujeros para sujetar algún ligero techado. La altura sería la suficiente como para moverse con cierta libertad sin quedar desprotegido.

\section{LA INSCRIPCIÓN}

Por último en lo que respecta a esta cara principal, está la inscripción que debe resolver monumento y relieves, y que se ejecutó, como es corriente en época romana en inscripciones rupestres junto a relieves, a uno de sus lados (preferentemente, como aquí, el izquierdo) y sin enmarcarlo en un campo epigráfico (por ejemplo en los relieves de la Fonte do Ídolo de Braga, Portugal ${ }^{11}$ ). La que estudiamos mide $68 \times 21 \mathrm{~cm}$. máx.; las letras de la primera línea

"Son pocos y poco profundos para sujetar un -andamio- (no es preciso estropear la superficie, pudiendo usar un andamio móvil), y cortos y mal ubicados para sostener antorchas (en el exterior no tienen sentido, y, aunque se pudieran sujetar, las dos inferiores quemarían necesariamente las superiores). Tampoco se puede pensar -en una pared interior de un templo- (?). Y, por último, no se me ocurre qué clase de apliqueornamental podría sujetarse aquí.

${ }^{10}$ En la citada fig. 2, este detalle concreto se ha tratado de resaltar utilizando gradaciones de los tonos grises.

${ }^{11}$ CIL II, 2419 y 2420 . Se trata de una roca viva, con el epígrafe del dedicante, la mención del dios, Tongonabiagus, y dos relieves: Una edícula y una figura masculina en pie, togada. Se suele aceptar su datación dentro del siglo I d.C. Ha sido publicado y estudiado muchísimas veces, v. por último J. M. Garcia, Religiöes antigas de Portugal, Lishoa 1991, 340-341, n. ${ }^{\circ} 174$, con fotos. 
$12 \mathrm{~cm}$., las de la segunda 6 (contando con las irregularidades propias del soporte y material). Al contrario de lo que opinó Knapp, los ductus no me parecen -pobres", sino relativamente bien hechos, especialmente en su zona izquierda (láms. 2b y 3a).

Todo el letrero, ejecutado inicialmente en época romana, fue retocado, en época medieval o moderna, con trazos sensiblemente menos profundos, para que, efectivamente, se leyera "A las tres/Marias", que es lo que vio el autor norteamericano. Además, aún más recientemente, y coincidiendo con los destrozos más arriba citados en el relieve de los animales, todavía ha sufrido algunos piquetazos y raspados, que hacen aún más difícil la lectura del original. En la fig. 3 se trata de definir las dos fases del proceso.

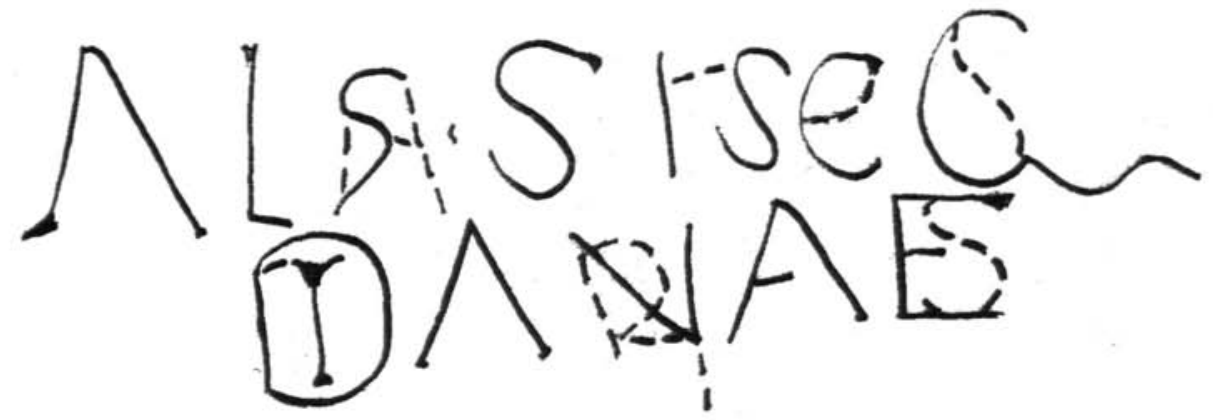

Figura 3. Fases posibles en los trazos de la inscripción: línea continua, la romana; línea discontinua, la moderna

Creo, pues, que la inscripción es también original y de época romana. Y, con muchas y debidas reservas, se puede leer:

\section{A(nimo) l(ibens) s(olvit votum) $\cdot$ Sisc(inius?) $Q(--)$ Dianae}

Las letras iniciales $A L S$ (con la $S$ claramente retocada para representar una $A-$ de "las pero con grabación más superficial) me parecen la clave para no poder dudar de que el epígrafe es votivo. Pero las letras siguientes pueden interpretarse también de otras formas, por su difícil lectura debido a los forzamientos para escribir encima tres. Por ejemplo, al final de la última línea hay un elegante trazo curvo, que debería corresponder a una $Q$, pero es difícil, tras convertirla en $S$ el reformador, distinguir bien el cierre de la circunferencia. Se podría entender también como un trianomina: S(extus) Isc(antius?) $Q(--)$ o como el propuesto duonomina. Paralelos para ambos gentilicios hay, aunque escasos: Siscinius en la provincia de Cádiz (Solin-Salomies 1988, 172), Siscius en África (ibid.) e Iscantius en Italia (ibid, 98). Si es cognomen la última $Q$, las posibilidades son muchas, pero las más comunes serían Quie- 
tus, Quadratus, Quintus y derivados. Que se trate de un libre o liberto va mejor con los ropajes de los sacrificantes del relieve ${ }^{12}$.

Es inexcusable mencionar lo extraordinariamente raro de que una inscripción votiva lleve la fórmula animo libens solvit a su comienzo en vez de a su final, si bien desde el punto de vista de la prosa latina nada se opone a ello y es muy difícil explicar de otra manera las claras letras de su inicio. No obstante, pueden aportarse, al menos, varios ejemplos del santuario galo-romano de Châteauneuf (Mermet 1993, núms. 37, 39, 61, 71). Sea como sea, mi propuesta de lectura queda abierta a otras más conformes con los muchos restos de trazos que se observan, pero siempre, creo, bajo el principio de que aquí están la fórmula de cumplimiento de un voto y el nombre del dedicante.

\section{UN EXVOTO A DIANA}

En cuanto a la línea segunda, la lectura más evidente es DVANAE, donde la $V$, aparentemente en nexo con la $A$, que se lee mejor, podría ser también una $I$ inclinada, o ésta ir encajada dentro de la muy destrozada letra inicial $D$, es decir, Dianae. Una fotografía tomada con fuerte luz lateral puede inclinarnos por la segunda opción (lám. 3a). Como existen muchas variantes en los epígrafes dedicados a esta diosa (la más frecuente Deana ${ }^{13}$ ), creo que, sea la forma originalmente escrita $\hat{D}$ ianae, $D<i>a n a e, \hat{D}$ uanae, lo importante es la atribución a la diosa hermana de Apolo de esta dedicación. Afortunadamente, se puede traer aquí a colación el comentario del hispano San Isidoro (Etym. VIII, 11, 56): Dianam autem vocatam quasi Duanam, quod die et nocte luna appareat, lo que me parece haría posible incluso aquí la variante Duana, sin corregir (aunque se trataría de un cultismo).

Estamos, por tanto, ante una edícula u oratorio rural y rupestre (y ello justifica su aislamiento de núcleos urbanos romanos), esculpido como exvoto y obsequio, quizá, del antiguo propietario de este predio, aprovechando una formación granítica natural, pero por demás llamativa, para consagrarla, junto con el sacrificio de dos animales (posiblemente blancos, como era costumbre), a Diana, la diosa greco-romana de la caza y los bosques, que contaba además con la faceta de protectora de las mujeres y por ello de la fecundidad ( $c f$. entre otros muchos títulos, $R E$ IX, 1903, col. 325 ss., con la bibliografía esencial). Las ofrendas usuales hacia Diana eran machos cabríos, cabritos blancos,

12 No me sorprendería que la abreviatura, o la misma palabra, votum, que falta aquí, se hubiera escrito en el mismo relieve del sacrificio, donde, en el espacio intermedio entre la pareja y la posible divinidad, creo ver gracias a los aumentos ciertos restos debilísimos de trazos (;XXXLCO/ (vac.) VOT?), pero sin que tengan bastante entidad como para decidirme a proponerlo.

13 Precisamente de la próxima Complutum, la actual Alcalá de Henares, también provincia de Madrid, procede $C I L$ II, 3025 (= Knapp 1992, n. ${ }^{\circ} 111$ ), la única otra inscripción a Diana de la Espana central, de texto Deanae sacrum, hoy perdida. Una posible lectura Dagae (aparente por la conversión de la $N$ en $R$ ) contaría en contra con no ser conocida tal divinidad indígena, pero a favor con la existencia en Villamanta (Madrid) de una gens Degantium o Deganticum (¿Dagantii?) (CIL II 3082 = Knapp 1992, 189 n. ${ }^{\circ} 214$, perdida), de donde vendría quizá el actual topónimo -Daganzo- de Madrid. 
jabatos y bueyes. De ahí que resulten muy coherentes con ella los relieves animalísticos que encontramos esculpidos debajo de la escena principal. Por la vestimenta elegida para la diosa y la presencia de una pareja oferente, me inclino a pensar en su advocación de Diana Lucina, protectora de los partos y, en general, de las mujeres.

\section{LOS PARALELOS: MALAMONEDA Y SEGÓBRIGA}

Paralelos recientes y próximos, en cuanto a la grabación de hornacinas en afloramientos graníticos naturales, son las dos estelas funerarias de cabecera redondeada de Malamoneda, prov. de Toledo, publicadas por G. Alföldy (Alföldy, 1991, 117 ss. $=A E 1991,1074$ a, b; e HEp. 4, 1994, 888), con los epitafios de dos Caecilii ${ }^{14}$. Este autor cree precisamente que pasaba por ahí la línea fronteriza entre Lusitania y la Hispania Tarraconense: $6 \mathrm{Km}$. al NO. de Hontanar, TO. y al E. del río Cedena (y cf. infra).

Pero para el más espectacular paralelo votivo con éste de Cenicientos, que creo nuevo oratorio rural de la melliza de Apolo, he sólo de recordar, pues es de todos conocido, el de las afueras de la ciudad celtíbero-romana de Segobriga, la llamada por Plinio caput Celtiberiae. Se trata del muy célebre "santuario rupestre de Diana", bien conocido desde antiguo. Sus cinco epígrafes pueden verse $s u b$ CIL II 3091-3093 y 5874. Fue ya descrito por A. de Morales, y en 1793 hizo J. Cornide, en ocasión de un viaje de estudio ordenado por la Real Academia de la Historia, un bello dibujo del llamado por él adelubro ó templo de Diana", y que ofrezco aquí (lám. 4) por encontrarse entonces los relieves en mucho mejor estado que actualmente (Cornide 1799, lám. 3). También es digno de mención el dibujo del natural del mismo sacellum, hecho por P. Quintero Atauri para su libro (Quintero 1913) sobre las antigüedades de la zona (lám. 5a, de Almagro 1983, fig. 17). El santuario ha sido reestudiado recientemente por M. Almagro Basch $(1976,1984)$ y por G. Alföldy $(1985,139-162 \text {, con láms. } 8 \text { a 10) })^{15}$.

Se trata de una pared rocosa, cortada casi en recto, que forma un abrigo natural, en el sitio llamado -del Almudejo", pasado el río Cigüela, al S.-SO. de Segóbriga y escaso $1 \mathrm{~km}$. de ella, a mano izquierda por la antigua carretera a Almonacid del Marquesado y frente a una antigua cantera. Se suceden en la pared cinco hornacinas grabadas, una medio destruída, tres de cabecera semicircular y una triangular. Bajo ellas, aún son reconocibles dos representaciones de Diana en su vestimenta más habitual, corta, de cazadora, acompañada por sus perros. En la parte inferior, cuatro epígrafes de libertos o libertas y uno de una esclava, con sendas dedicaciones votivas ${ }^{16}$. En dos ocasiones se la llama Frugifera y Nicephora (pace Alföldy, loc.cit.:

${ }^{14}$ Agradezco a la Dra. H. Gimeno el haberme recordado este reciente hallazgo.

15 Ambos ofrecen abundantes fotografías, que demuestran el considerable estado de deterioro que han sufrido relieves y epígrafes con el paso de los años. En una visita hecha en enero de 1996, se aprecian nuevos y graves deterioros en los relieves.

$16 \mathrm{G}$. Alföldy (loc.cit.) recuerda la estrecha relación de esta diosa con esclavos y libertos, a raíz de la ubicación de su famoso templo en el monte Aventino de Roma; y en el barrio que, cuando ya estaba construído (en época de Servio Tulio) fue atribuído ( 456 a.C.) a plebeyos y gentes humildes. Este santuaric, de culto federal romano-latino (commune Latinorum Dianae templum lo define Varrón), es llamado por Festo y Censorino aedes Dianae in Aventino (cf. RE, cit., col. 332). 
Nicephoris?). En un ara aparecida en el vecino Almonacid se la llama Diana Domina (CIL II, $6833 \mathrm{~m}$; Almagro $1984,59 \mathrm{n} .^{\circ} 2$ ), lo que parece apuntar a un culto no solamente local.

Tendríamos, por tanto, en la gran "Piedra Escrita" de Cenicientos, una nueva manifestación rural (y, salvando las distancias, sí muy similar en la concepción a la segobriguense) de culto a la que es segunda divinidad en importancia en la religiosidad de los hispanos por el número de sus dedicaciones, detrás sólo del propio Júpiter (Vázquez 1982a, 170 y 1982b, mapa 26). Como esta autora bien concluye, tres cuartas partes de las manifestaciones de todo tipo del culto a Diana lo fueron en territorio lusitano, si bien en lo epigráfico la misma provincia queda muy atrás, con sólo tres ejemplos (Pena 1982, 56) aunque es seguro que se le dedicaron con preferencia lugares abiertos o bosques, puesto que uno de sus más antiguos lugares sagrados fue precisamente su bosque de Nemi, en Italia (de donde su epíteto de Diana Nemorensis). Parece claro que los ejemplos de Segóbriga y Cenicientos irían muy apropiadamente a esta categoría.

No cabe descartar que este monumento forme parte de un lugar de culto más extenso y complejo. En este sentido hay que recordar el importantísimo santuario de Panóias (Ourique, Port.: $c f$. por último Alföldy, 1995, con la numerosa bibliografía anterior). Pero esto es algo que sólo una prospección extensa y profesionalmente hecha podría dilucidar.

\section{EL ENTORNO}

Parece claro que población inmediata al monumento en época romana no se puede detectar. Mangas et al. señalaron la existencia en esta elevación de "fragmentos de cerámica de diversas épocas, siendo más abundantes las medievales y apareciendo en menor número las de época romana... algunos fragmentos de cerámica común", aunque pensaron que podía haber en los alrededores algún edificio, pues observaron algún que otro sillar toscamente escuadrado.- J. Zozaya (apud Knapp, op.cit.) creía que los restos eran muy exiguos.

Sólo en la información periodística aparecida en "El País* del 12-10-1995 se mencionan otras dos noticias interesantes, cuya fuente es local. La existencia de -una veintena de tumbas antropomorfas, de 1.90 de longitud y $0.70 \mathrm{~m}$. de ancho... ruedas de molino y tejas", que serían testimonio de un poblado levantado "cercano al menhir" en el siglo XVI y que duró hasta 1720. Según los archivos parroquiales, tenía su propia parroquia y una patrona, que -se llamaba, por supuesto, la Virgen de la Piedra Escrita-. En cuanto a los cuatro sondeos arqueológicos (Morón-Mompeán 1995), los resultados no pueden ser más decepcionantes ${ }^{17}$, pero se indica

\footnotetext{
${ }^{17}$.Poco material... pequeños fragmentos de cerámica común... pocos fragmentos cerámicos y de escaso valor... escasos fragmentos cerámicos y algunos restos óseos..., para concluir que -los materiales cerámicos encontrados en la excavación no han posibilitado la determinación exacta de la época cultural a la que pertenece el presente yacimiento (monumento y entorno cercano), aunque abunda la cerámica de época romana (sigillata).
} 
que la cerámica más abundante es la sigillata romana (aunque no se dice qué tipo y fecha de ella), y que se documenta también cerámica medieval, común y vidriada, entre ella un fragmento de "de cerámica musulmana". Es más singular la mención de "varios fragmentos de escoria en los sondeos 1 y 3 ."

Con estas pocas referencias más la observación propia, no parece que en las inmediaciones mismas de -Piedra Escrita hubiera nunca un núcleo estable de población. Las tumbas medievales excavadas en la roca son frecuentes cerca de focos religiosos y funerarios romanos aislados, como es éste el caso. Las encontramos también, más de un centenar, en un área de $1 \mathrm{~km}^{2}$ en torno al canchal que rodea al peñasco con estelas de Malamoneda, TO., ya citado (Alföldy 1991, 118). Incluso el propio peñasco, con las dos estelas en su cara O., presenta una sepultura excavada en su parte superior.

Pero tales tumbas deben corresponder en mi opinión no al poblado o aldea del siglo XVI-XVII que se documenta a través de los archivos parroquiales de Cenicientos, sino al hábitat medieval que quizá precedió al citado, aunque no se conserven los documentos escritos. El poblado, con la Virgen de significativo nombre pero sucesora de la Diana romana, tenía por fuerza que haber dejado más rastros que los que en la superficie actual se conservan.

\section{PIEDRA ESCRITA Y LA DIVISORIA PROVINCIAL ROMANA}

Se ha apuntado ya que la pieza podría señalar por este punto el finis entre dos conventus judiciales y provincias (A. Fuentes, en "El País" 14-10-1995). Tal papel en principio lo podría cumplir incluso sólo con otra contigua, pues ésta podría ser un ara terminalis, al modo de los gromáticos. Pero, por una parte, efectivamente, la zona coincide con límites actuales entre Madrid y Toledo. Discrepando del límite senalado en la TIR, que creo avanza en exceso y sin motivo hacia el Oeste ${ }^{18}$, parece más bien que éste debería marcarlo la línea de la Sierra de la Higuera, con las Peñas de Cenicientos y Cadalso, de 1254 y $1044 \mathrm{~m}$. de altura respectivamente, ya que estas alturas montañosas definen las cuencas del Tiétar-Duero hacia el NO., y la del Alberche-Tajo, hacia el SO. Es en esta vertiente meridional en la que se encuentra -Piedra Escrita.

Se me ocurre, pues, que pueda proponerse una relación entre este monumento y, por una parte, los Toros de Guisando ${ }^{19}$, situados unos $15 \mathrm{Km}$. en línea recta hacia el N. de -Piedra

${ }^{18}$ Esta obra está recibiendo muy duras críticas. De su primera entrega, hoja K-29 (Porto) $c f$., por ejemplo, las de J. C. Rivas $(1993,294)$ o J.-G. Gorges $(1992,127)$. La segunda, K-30 (Madrid) tampoco sale de momento muy bien parada, $c f$. E. de Carrera $(1994,155)$. Como pequeñas muestras, valgan la sorprendente ausencia en el mapa del lugar donde se conservan los Toros de Guisando o, en la bibliografia, la consulta de la obra de R. C. Knapp (1992), fundamental para la Espana Central en lo que a la epigrafía y sus yacimientos se refiere.

${ }^{19}$ No quisiera dejar escapar esta ocasión para llamar la atención sobre el estado de abandono en que la Junta de Castilla y León mantiene este lugar. Las cuatro esculturas, ya muy maltrechas y con algunos letreros borrados, carecen de protección alguna frente a miles de visitantes, muchos de los cuales los utilizan como montura. 
Escrita- ( $c f$. infra), y, por otra, con el citado yacimiento de Malamoneda, también alineado con él, hacia el S., a una distancia de unos $50 \mathrm{Km}$.

La zona intermedia entre Cenicientos y Hontanar está poco estudiada, por lo que quizá un análisis más detenido del territorio aportaría más datos al respecto. Pero, de momento, me gustaría acudir ahora a las, no por ya lejanas menos válidas, obras de $\mathrm{F}$. Braun (1909, 116-117) y E. Albertini (1923, 19). Braun pensaba, muy justamente, que Caesarobriga (Talavera de la Reina, TO.) era lusitana y Toletum (Toledo) tarraconense, luego entre ambas debía discurrir la divisoria provincial. Recordaba entonces la ciudad de Libora, mencionada como tarraconense por Ptolomeo entre Toletum y Augustabria (II, 6, 56) y aún citada por el Ravennate $(312,11)$ como Lebura (Tovar 1989, 235: no es la misma que Aebura). Ukert y Bosch pensaron ubicar esta Libora en Cuerva (TO.), demasiado lejos del Tajo para Braun. K. Müller en Puebla de Montalbán, sobre el río, idea que comparte el propio Braun, quien anade que, junto al Tajo, debía estar más cerca de Talavera que de Toledo ( ibid. 117). En cuanto a Albertini ( bid.), creía que la línea cruzaba el Tajo "aguas abajo de Toledo".

Es, pues, en este punto, donde quisiera traer a colación un hallazgo reciente que parece dar la razón a Braun. A comienzos de 1975, se encontró en el término de Puebla de Montalbán, en el sitio de Cerrecín (margen derecha del Tajo) un verraco sobre plinto, de granito, de $85 \mathrm{~cm}$. en cuadro, junto a parte de una estela fragmentada de caliza, de remate semicircular y con una roseta, de buenas época y calidad, ornamental y epigráfica ${ }^{20}$. Se trataría, pues, de otra zona funeraria en coincidencia con figura de verraco, y posiblemente limital. Este hallazgo creo que reforzaría, si no la idea de Braun de que Libora/Libura coincida con la actual Puebla de Montalbán (que necesitaría algún otro apoyo epigráfico ${ }^{21}$ ), sí la de que, en efecto, ligeramente a su Oeste cortaría el Tajo la divisoria entre Citerior y Lusitania.

A falta de más datos objetivos suficientes, parece poderse postular que la frontera entre las provincias Lusitania y Citerior Tarraconense discurría, rectamente, por aquí, y que esta línea procedía, casi en línea recta, desde Arévalo, en Ávila (cf. infra). Y, si fuera cierta la presencia en -Piedra Escrita- de un verraco ( $c f$. excursus, infra, parág. 11), esta idea se vería en mi opinión reforzada ${ }^{22}$. Por esta zona sur, al menos la divisoria podría prolongarse, poco menos de $6 \mathrm{~km}$. al S. de Hontanar, entre las alturas, muy expresivas, de "Corral de Cantos" (1419 m. altitud), si se entiende el término cant- (como he defendido en otro lugar, a propó-

${ }^{20}$ El hallazgo se adelantó en el diario -Ya-, de 19-2-1975, con fotos del epígrafe (inscripción funeraria, de buena época, de un Medugenus) y del verraco (se conserva en el fichero del CIL II ${ }^{2}$, U.C.M.) y fue luego publicada, sólo la inscripción, por J. Martín Aragón, Toletum 61, 8, 1974-1976 [1977], 91, con foto. Al mes siguiente, marzo de 1975, ingresó la inscripción (no sé si el verraco también) en el Museo de Santa Cruz, de Toledo; la recogen S. Cortés et al. en Museos 3, 1984, 78, fig. 7 ( $A E$ 1986, 429). Otra inscripción, aparecida cerca y posteriormente ( $c f$. HEp. 2, 1990, 690), también semicircular y con roseta, confirma la peculiaridad de este taller. candidatas.

21 La localidad de Carpio de Tajo, así como alguna otra próxima, de menor entidad, también serían

22 Me han llegado noticias más recientes sobre la existencia de otro verraco en el municipio de Real de San Vicente. 
sito del río Cantia, actual Chanza, en la Beturia Céltica: Canto 1997, e.p.) como borde, límite, frontera, y "Sierra de las Particiones" $(1233 \mathrm{~m}$.), $9 \mathrm{Km}$. al O. del alto del Corral de Cantos (donde se produce el divergium aquae entre las cuencas del Tajo y el Guadiana). Ambos topónimos podrían ser expresivos de una vieja divisoria romana. Y no es menos curioso que el cerro intermedio entre ambas alturas, de 1190 m., se denomine justamente -El Puerco"; resto, imagino, del recuerdo de algún verraco que allí se levantara en la antigüedad. En esta vertical, al menos, el papel de los verracos en relación con las fronteras abre interesantes posibilidades de estudio ( $c f$. para el tema Álvarez-Sanchís, 1993, 165).

Esto en cuanto a la línea fronteriza meridional. Mirando ahora hacia el Norte de Piedra Escrita, conviene citar un trabajo que acaba de publicarse (Hernando 1995), del que tengo noticia estando ya éste terminado. La autora propone, con argumentos convincentes de distintos tipos, que la actual ciudad de Ávila (posiblemente Abela) no sería idéntica con la Obila de Ptolomeo, y pertenecería, frente a lo que se viene creyendo ( $\mathrm{v}$. lo citado más arriba y, por último, TIR, cit.), no al convento cartaginense y la provincia Citerior, sino al emeritense y la provincia lusitana (ibid., 93, lám. II; parecida idea en Knapp 1992, 6-7). El Sistema Central resulta, en efecto, un límite natural demasiado fuerte como para defender el aislamiento de la zona abulense del resto de su convento, además del sentido general del sistema viario romano, que Hernández Sobrino valora adecuadamente. Siguiendo más o menos hacia el N. el cauce del río Cofio (confinium), se cita en esta zona, entre Cebreros y Las Navas del Marqués, otro curioso verraco, quizá antiguo, sobre el que se inscribió un epígrafe limital, posiblemente moderno ${ }^{23}$ (Knapp 1992, 7 y 307; Hernando 1995, 89 con n. 54).

De esta forma, nuestra línea fronteriza antes propuesta, Guisando (AV.)-Cenicientos (M.)-Puebla de Montalbán-Hontanar-Corral de Cantos/Alto del Puerco (TO.), vendría, más al N., desde Arévalo (AV.) a tener también una continuación septentrional coherente con la divisoria recién propuesta. En la fig. 4 reflejo la hipótesis de estos casi $140 \mathrm{Km}$. de frontera.

\section{CONCLUSIÓN Y CRONOLOGÍA}

En resumen, parece lo más probable que en época romana el monumento de Cenicientos estuviera tan aislado como lo está hoy, aunque no cabe descartar que cerca pudiera haber alguna necrópolis de finca o fundiaria. Su función primordial sería la de ser un exvoto religioso, el cumplimiento de la promesa de un particular, esperando o agradeciendo un favor de la divinidad, y que el paraje, de posible coincidencia fronteriza, terminara por convertirse en sagrado y lugar de oración para las gentes de su entorno. Esto justificaría la presencia de las sigillatas. Con este carácter llega a la Edad Media,

${ }^{23}$ La reducción cofinium $=$ Cofio para hidrónimos asturianos, se debe a Sánchez Albornoz (Knapp 1992, 7). El epígrafe es CIL II, 279*: Conocido sólo por un manuscrito, diría, por un lado, Hic est Tarraco et non Lusitania; $\mathrm{y}$ por el otro Hic est Lusitania et non Tarraco. Aun dando las inscripciones por modernas (el zoomorfo bien pudo ser antiguo), son perfectamente lícitas a los efectos de suponer el recuerdo en esta zona de la vieja frontera, como hacen Knapp y Hernando Sobrino. 


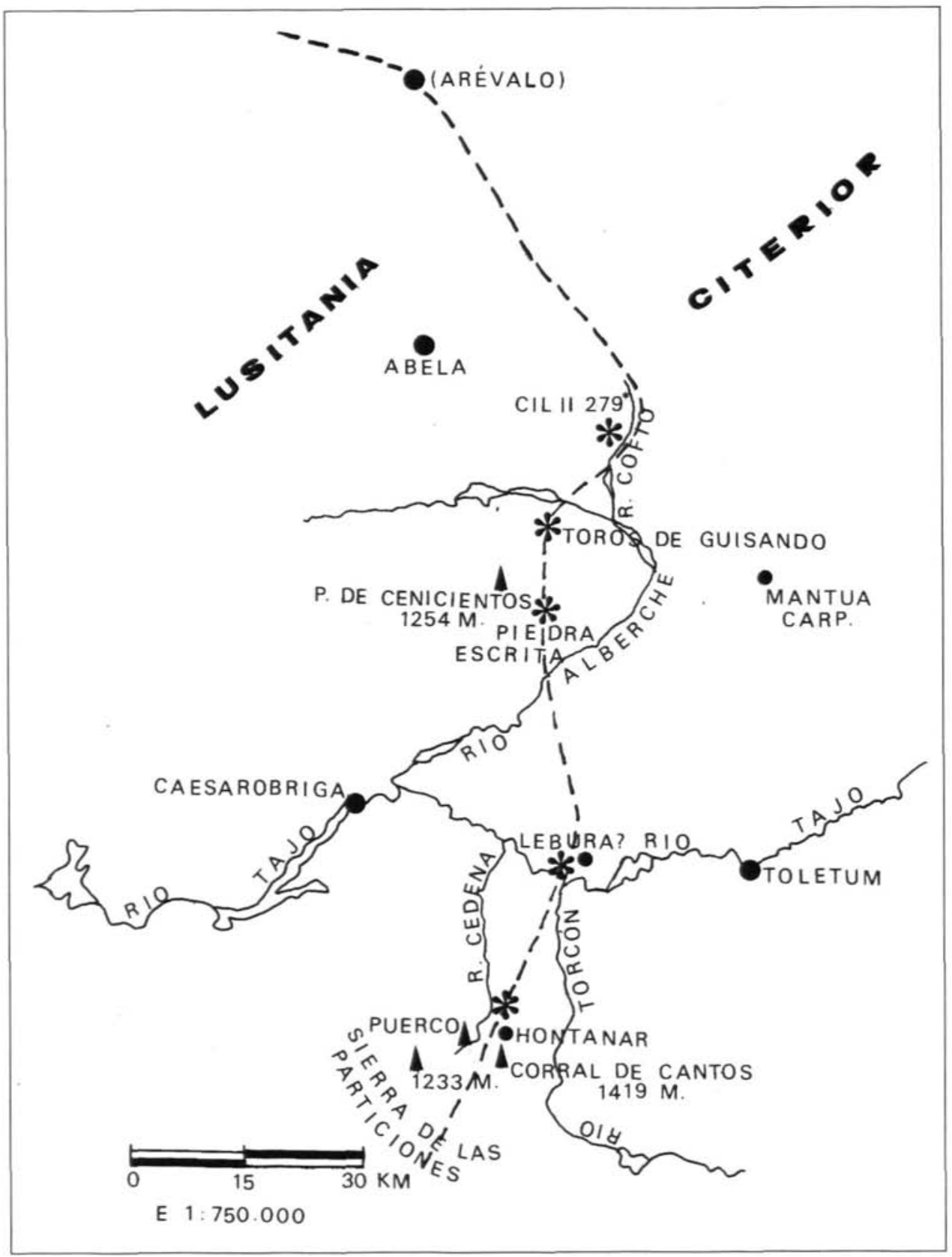

Figura 4. Propuesta de restitución de fronteras; los asteriscos señalan hallazgos de verracos y/o inscripciones sepulcrales o votivas 
en la que se empiezan a enterrar en sepulturas excavadas en los canchales próximos (como ocurre en otros casos) y debió haber alguna pequeña ermita que perpetuara la santidad del lugar (ello explicaría también la presencia pero en poca cantidad de la cerámica medieval). Quizá en torno a ella se creara una pequeña aldea, con la ermita convertida en la Parroquia de Ntra. Sra. de Piedra Escrita, la que se cita en los archivos del siglo XVI. Quizá entonces, o mucho después, un pastor aprovechara la forma de muro casi recto de la gran peña para construirse un provisional abrigo.

Parece inexcusable hacer referencia al problema de la datación, salvado el hecho indudable de que relieves y epígrafe son romanos. Los elementos con que contamos para una mayor precisión son escasos. Mangas et al., seguidos por la TIR, atribuyeron monumento e inscripción (por tener la misma pátina) a los siglos II o III d.C., Knapp prefirió el siglo II para los relieves, mientras que la inscripción original estaría perdida, y la que hoy se ve sería para él medieval. Los sondeos arqueológicos sólo nos aportan el dato impreciso de la existencia de sigillata. Los tipos de vestidos (mantos, túnicas y toga) y ajuar (pátera, jarro, posible sistro) se mantienen relativamente estables, por lo que no resultan muy indicativos a efectos cronológicos.

La epigrafía sobre granito siempre aporta la dificultad añadida para la datación de que no es posible ceñirse en las grafías a estilos bien fechables. No obstante, la relativa anchura, cuadratura y corrección de algunas letras (A, D, S, E) y el inconfundible remate de la Q, me llevan a preferir como fecha de ejecución del monumento de "Piedra Escrita" un momento dentro del siglo II d.C., cuando ya era posible que el culto de la Diana romana estuviera arraigado en este aislado lugar, y seguramente interpretado hacia ella desde una divinidad indígena previa y similar.

\section{Excursus: El "oso" y el "verraco"}

Me restan por comentar dos aspectos más en torno a este enorme exvoto: su parte trasera y un detalle de su entorno inmediato. Pero deliberadamente he querido separar esta parte del trabajo de la anterior, porque que aquí voy a usar quizá en exceso de un ingrediente que me parece imprescindible para la investigación: la imaginación. Pues no me parecería adecuado sumarme a las especulaciones ya publicadas o pasarlas en silencio, si creo tener otra, aunque pueda parecer también descabellada, ni tampoco omitir algún detalle suplementario que pueda ayudar a la mejor comprensión del monumento.

\section{EL OSO}

Como ya apunté brevemente al principio del trabajo, la zona trasera de esta gran roca granítica, en general mucho más tosca si se compara con la principal, presenta una serie indudable de oquedades y retoques, a los que se puede calificar de completamente intencionados. Las oquedades, de forma circular, se han interpretado como -orificios co- 
rrespondientes a vigas de una techumbre a dos vertientes" (TIR, cit.), y como "una escalera que permitía la subida con el fin de hacer sacrificios". Al no tener sentido la primera propuesta, y no tratarse, para la segunda, de un monumento que haga creíble tal función (como sí ocurre, por ejemplo, en los santuarios rupestres de Ulaca, Ávila, o el citado de Panóias, en Ourique, Portugal, ni existir en su cima espacio suficiente o cómodo para tal actividad, he tratado de encontrar otra explicación para ellos.

Observándolos con detenimiento, a simple vista, con luz normal y mejor con el sol rasante del atardecer (lám. 3b), puede verse que las oquedades no son tan profundas como para permitir apoyar con seguridad el pie $^{24}$ (ni mucho menos vigas), y también que en realidad los huecos no se disponen en forma "escalonada", sino en una corona que tiende al óvalo, enmarcando precisamente un abombamiento natural de la propia piedra. Éste a su vez presenta un trabajo intencionado de cincelado a su alrededor, como para destacar aún más lo que podría interpretarse como la almohadilla central de la pata delantera de un plantígrado. Desde esta óptica, el conjunto se entiende con bastante claridad, en "positivo" y "negativo-, como la huella de un oso.

No se crea que para mí misma es una hipótesis sencilla de aceptar: Si acaso es la única que encuentro. Pero, como es bien sabido, el oso fue en la antigüedad el animal, cazador y cazable, por excelencia. Y, por ello, aprovechar ingeniosamente una forma natural de la misma roca donde se efectuaba una dedicación a la diosa Diana para incluir a otro más de los animales que le estaban consagrados no me parece una idea tan descabellada (sobre todo si se confronta con la siguiente).

Y, de todas formas, citaré como oportuno paralelo el famoso conjunto de bronce, procedente de Muri, cerca de Berna (Suiza), que se conserva en el Museo Histórico de esta última ciudad helvética. En el exvoto se representa a la diosa Artio, el trasunto céltico de Diana en su vertiente de diosa de la caza, pero no con su más usual atavío cinegético, sino (como en Cenicientos) con túnica y manto, además de cornucopia, sentada frente a un enorme oso, con el que parece dialogar (Green 1989, 27 y fig. 10). Artio, en lengua céltica, significa precisamente "oso" (lám. 5b).

\section{Y EL VERRACO}

No menos me sorprendió otra observación, ésta también desapercibida para todos los que han visitado antes "Piedra Escrita". Exactamente delante y de frente al gran peñasco, y a unos pocos metros de distancia, existe otra gran piedra granítica y alargada. Mide de un lado al otro aproximadamente $4.30 \mathrm{~m}$., y de alto 1.10 . No parece estar in situ, sino desplazada y calzada con varias piedras menores por su lado sur. Lo curioso es que, si uno se sitúa de espaldas al relieve de «Piedra Escrita", esta roca, vista de frente ${ }^{25}$, semeja exactamente un verraco suido, recostado (lám. 3c).

$2 i$ Por comprobación experimental.

25 Hay que advertir que, vista desde el otro lado, el S., cuando uno se aproxima a ella, la gran piedra carece de todo sentido. Sólo lo tiene vista, digamos, desde y frente a la posición de la misma diosa. 
¿Por qué no admitir que, frente al monumento a Diana, se ubicara una enorme piedra que, por capricho de la naturaleza, recordaba al segundo de sus animales más representativos, el jabalî? También en este caso contamos con el consiguiente paralelo del mundo céltico: la diosa gala Arduinna, protectora y homónima de los bosques de Les Ardennes, en Francia, y especialmente vinculada al jabalí (objeto favorito de caza), a cuyos lomos aparece cabalgando en un pequeño bronce local (Green 1989, 27 con nota 106: Boucher 1976, 161 y fig. 292).

Pero no es preciso recurrir sólo a los paralelos galos. La abundancia de caza en la Hispania romana está fuera de duda y, en ella, el jabalí ocupa lugar primordial, al punto de ser representado de forma extraordinariamente frecuente, y con fines muchas veces funerarios, en los famosos verracos (unas veces toros, otras suidos), propios y populares precisamente en el territorio vetón (120 sólo en la provincia de Ávila, quizá el doble sumando los de Salamanca y Cáceres: Knapp 1992, 321).

En este sentido, cabe recordar los trabajos de G. López Monteagudo (1982) y R.C. Knapp (1992), resumiendo las muchas hipótesis sobre el origen, función y cronología de este tipo de esculturas. Entre la señalización de fronteras (que sería herencia de la función dolménica ${ }^{26}$, según recientes teorías), el símbolo apotropaico y protector, y el uso funerario al modo de cupae continúan moviéndose las hipótesis. Pero su papel de hitos en las líneas fronterizas, como más arriba indiqué (epígrafe 9) con varios ejemplos y topónimos, sale en mi opinión reforzado con los datos de este estudio.

No me resisto, para terminar, y porque menciona el municipio de Cadalso de los Vidrios, cerca de Cenicientos, a traer a colación un texto, curioso y fantástico, del siglo XV, recordado por R.C. Knapp $(1992,321)^{27}$, en el que se cita a los verracos como trofeos:

-...Después de que Escipión el Joven volvió a Roma (205 a.C.), y después de su muerte, los españoles se rebelaron contra los romanos; éstos enviaron a España un capitán llamado Guisando, que habiendo peleado contra los españoles en Tierra de Toledo y cerca del lugar llamado Cadalso, y habiéndolos vencido, bizo, para memoria de esta victoria, cuatro estatuas de piedra, a manera de toros, a las que en su tiempo daban el nombre de Guisando...

Como Knapp bien señala (ibid., 322), los Toros de Guisando están hoy en el término de El Tiemblo, marcando exactamente, en la "Venta Juradera" de la católica reina,

${ }^{26}$ No quiero dejar de mencionar que, continuando un kilómetro más adelante por la misma carretera Cenicientos-Almorox, y en el punto preciso por donde se señala el límite de Madrid con Toledo, se encuentra una vereda a la derecha, que es la teórica continuación de una vieja carretera a Cadalso de los Vidrios (que no encuentro hoy en varios mapas de carreteras, a pesar de que está en uso). A pocos metros de iniciarse el carril, a la izquierda, hay una formación granítica que semeja, incompletamente, un círculo dolménico. Sería preciso para comprobarlo efectuar algún pequeño sondeo. Este punto se alinea, escasos kilómetros más acá, con -Piedra Escrita-

${ }^{27}$ El texto se debe al historiador D. Rodríguez de Amelta, Compilación de las batallas campales, 1481, y se citó originalmente por P. Arias, M. López y J. Sánchez, en Catálogo de la escultura zoomorfa protobistórica y romana de tradición indigena de la provincia de Ávila, Ávila 1986, 149 con nota 18. 
el límite entre Ávila y Madrid. Este punto se encuentra al N., a poco menos de $15 \mathrm{Km}$. en línea recta, de sPiedra Escrita. Conclusiones acerca de la función limital de estos verracos, por tanto (y, como dije, en posible relación meridional con Malamoneda, Puebla de Montalbán y Corral de Cantos-El Puerco) serían posibles.

\section{ADDENDUM}

En imprenta ya este trabajo, creo haber encontrado una fuente antigua y fiable que vendría a confirmar mi hipótesis previa sobre la posible huella de oso en la trasera del monolito de -Piedra Escrita- (cf. supra parágrafo 11). Se trata de Latinus v.p. Togatus, uno de los agrimensores antiguos reunidos en el corpus de K. Lachmann (Gromatici veteres, Berlín, 1848, p. 309). El texto describe distintos tipos de monumentos terminales (es decir, divisorios), y entre ellos éste: Terminus sive petra naturalis, si branca ursi babuerit, lucum significat, por tanto: "Si en un cipo divisorio o sobre una piedra natural se representara una garra de oso, significa (el comienzo de un) bosque, remitiendo a su fig. 250 (que aquí más abajo se reproduce). Afortunado paralelo para el caso de Cenicientos, puesto que, en efecto, no sólo la garra de oso podía perfectamente utilizarse para señalización sobre una piedra natural, sino que además estaría especialmente indicada aquí para marcar un lucus Dianae, patrona y protectora de los bosques y uno de cuyos animales simbólicos, como más arriba decía, es el oso. Se refuerzan así también la lectura del epígrafe y el doble carácter de "Piedra Escritav, como exvoto/hito divisorio. En tal caso, los bosques sagrados que a partir de ella comienzan llegarían al menos hasta las Sierras de la Higuera y San Vicente, al Oeste. Con este paralelo creo que el monumento, su entorno y su finalidad quedan más sólidamente interpretados. Me permito en fin, y por ser muy oportuna, recordar esta otra frase de Boethius (Demonstratio artis geometricae, apud Lachmann, op.cit., 403: "Termini vero non sunt omnibus locis, sed infinita

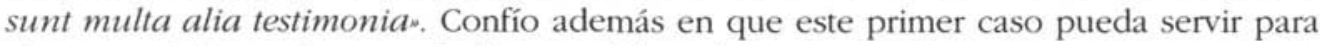
el reconocimiento de otros similares en Hispania.

\section{LATINUS TOGATUS}

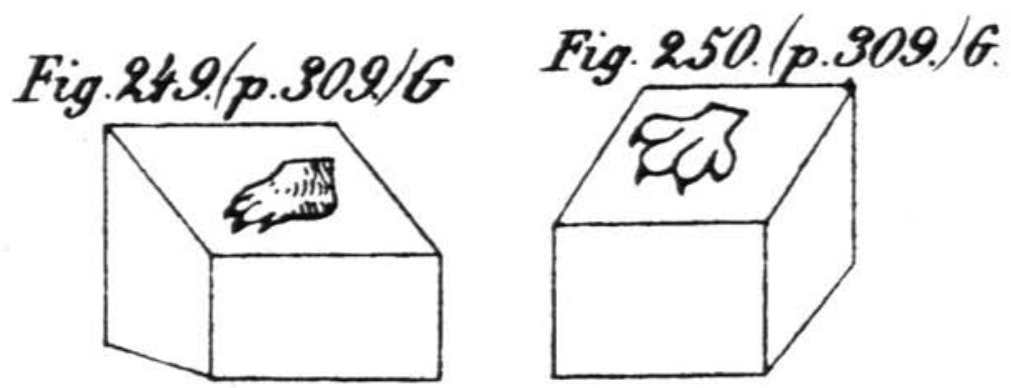

Figura 5. Ejemplos de termini gromáticos con patas de lobo y oso (según Lachmann, fig. 250) 


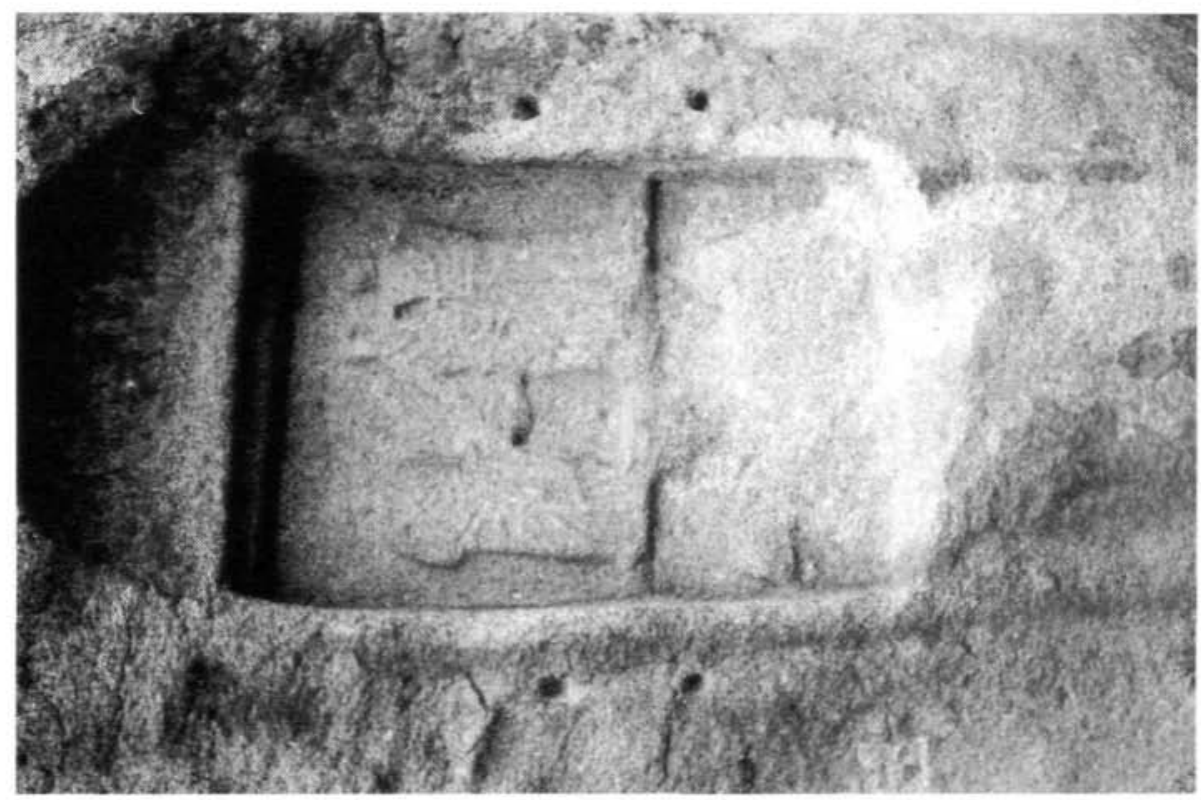

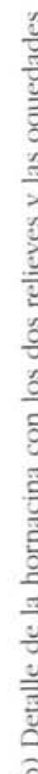

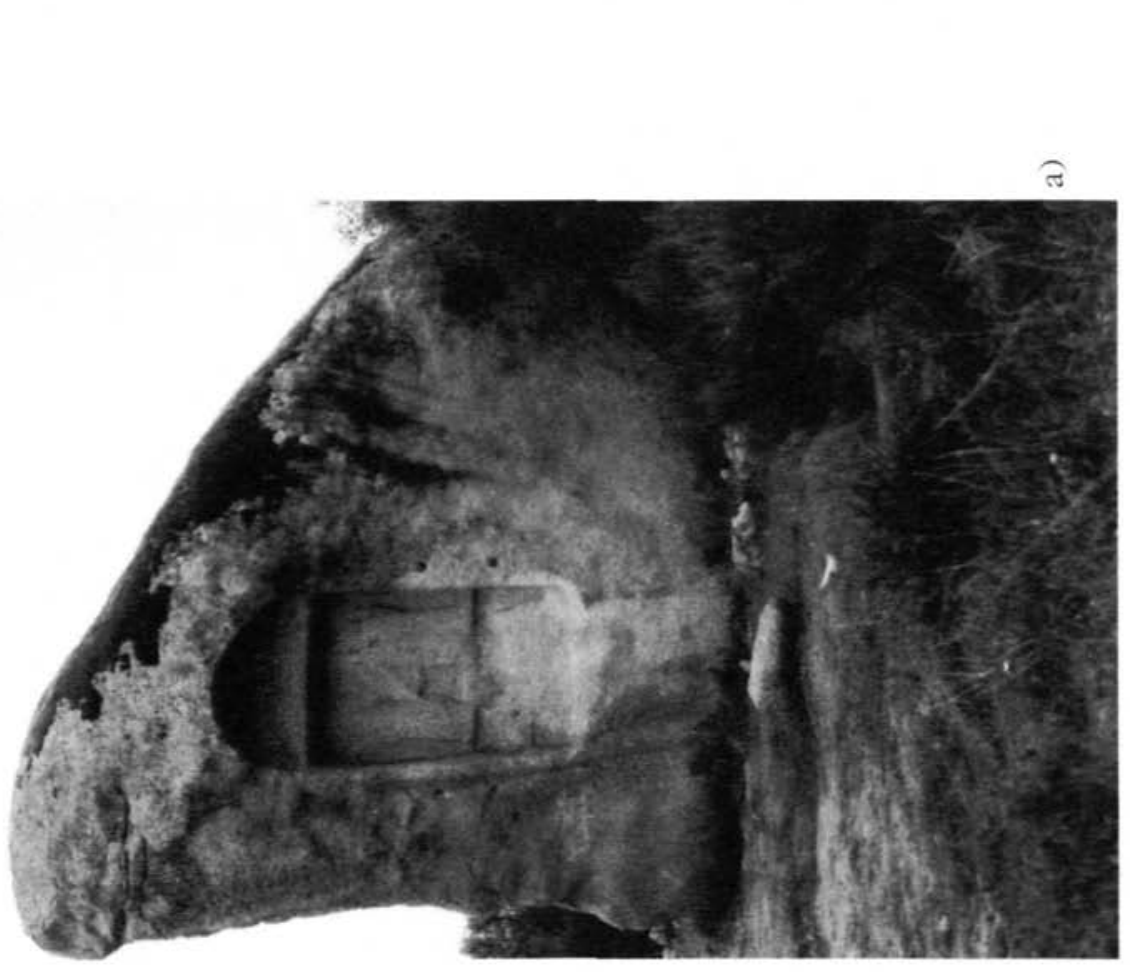




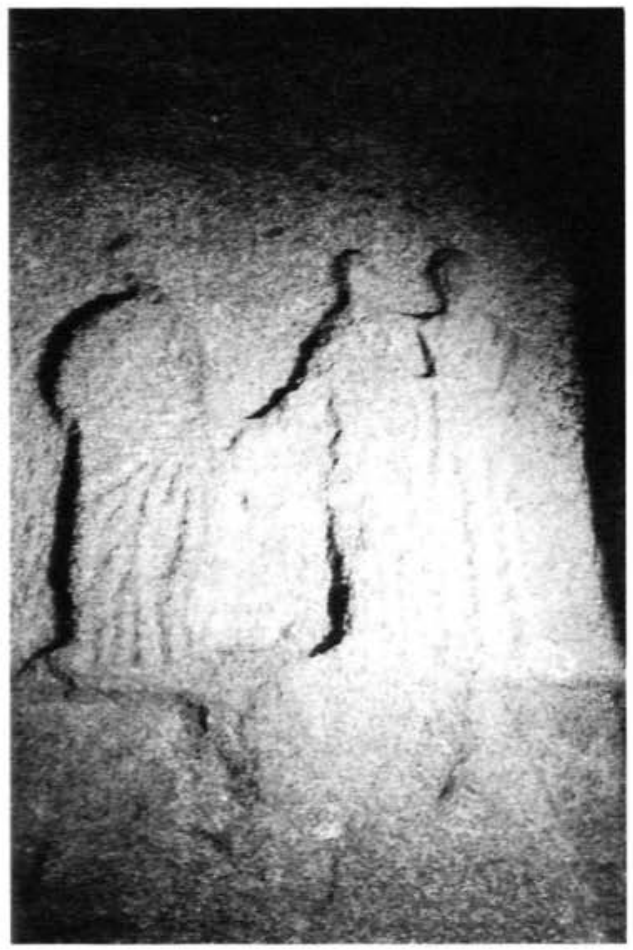

a)

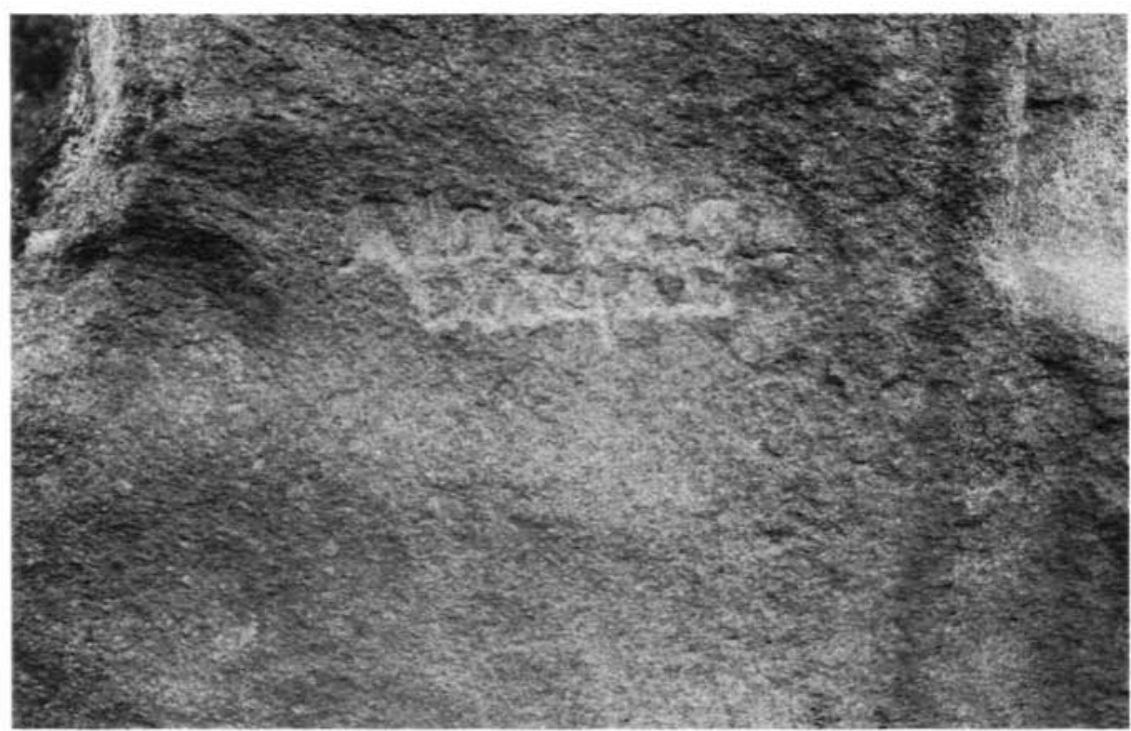

b)

Lámina 2. a) Detalle de los relieves. b) La inscripción, aspecto general 


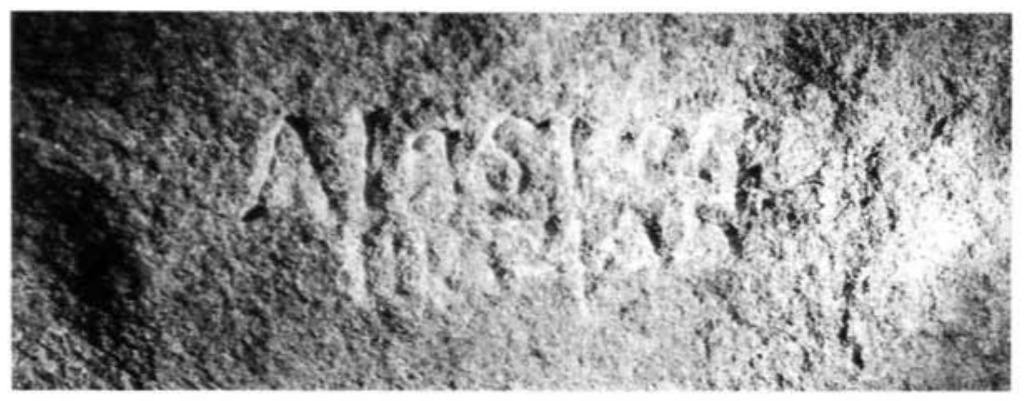

a)

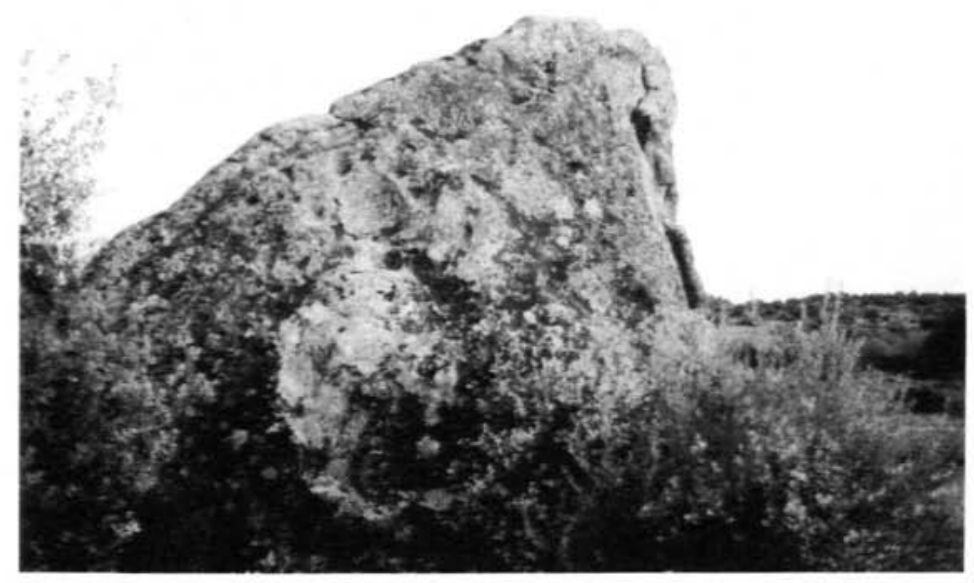

b)

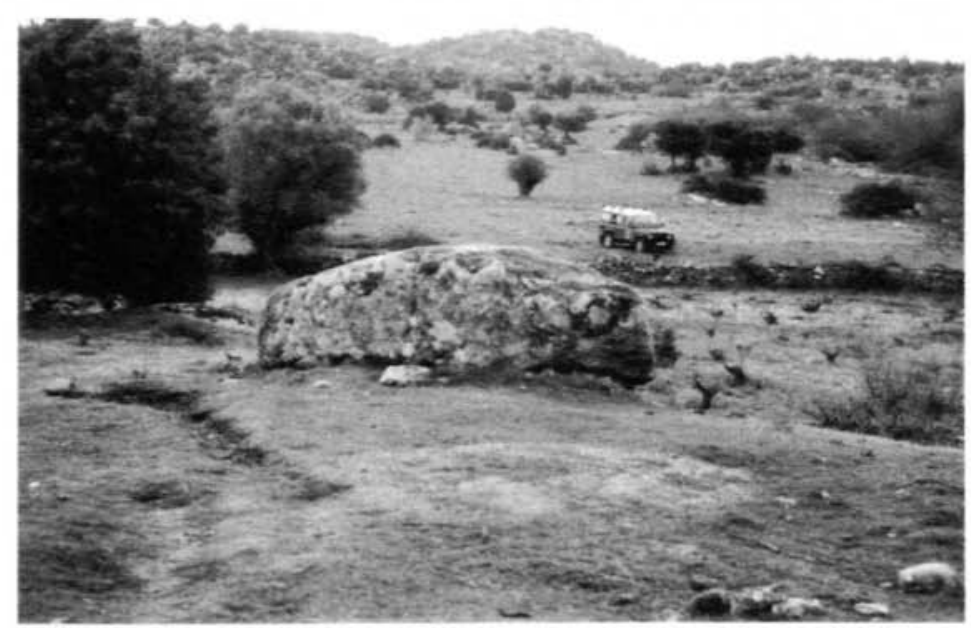

c)

Lámina 3. a) Detalle del epígrafe y sus retoques. b) Cara posterior con la supuesta huella. c) Granito natural con forma de verraco 


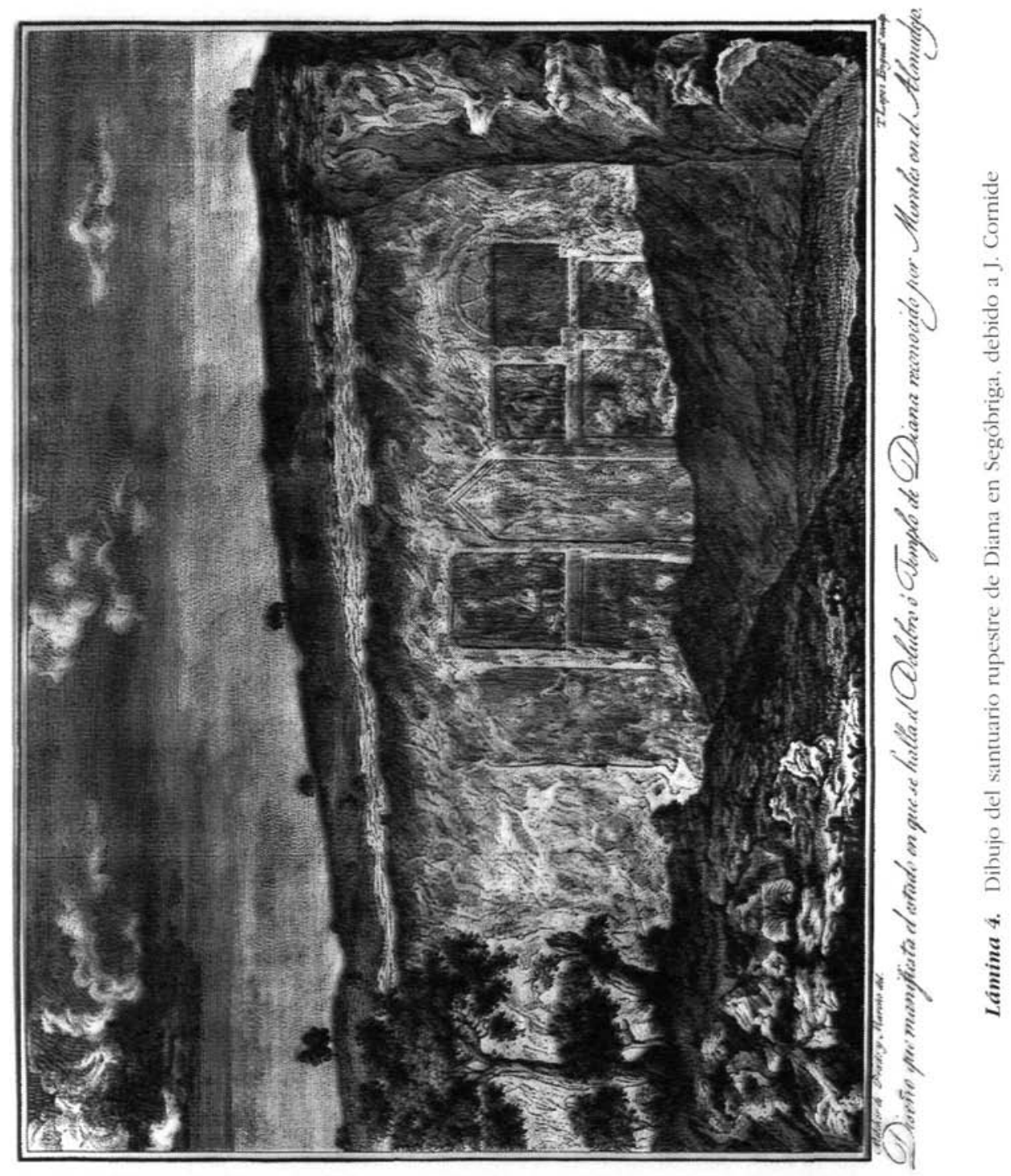




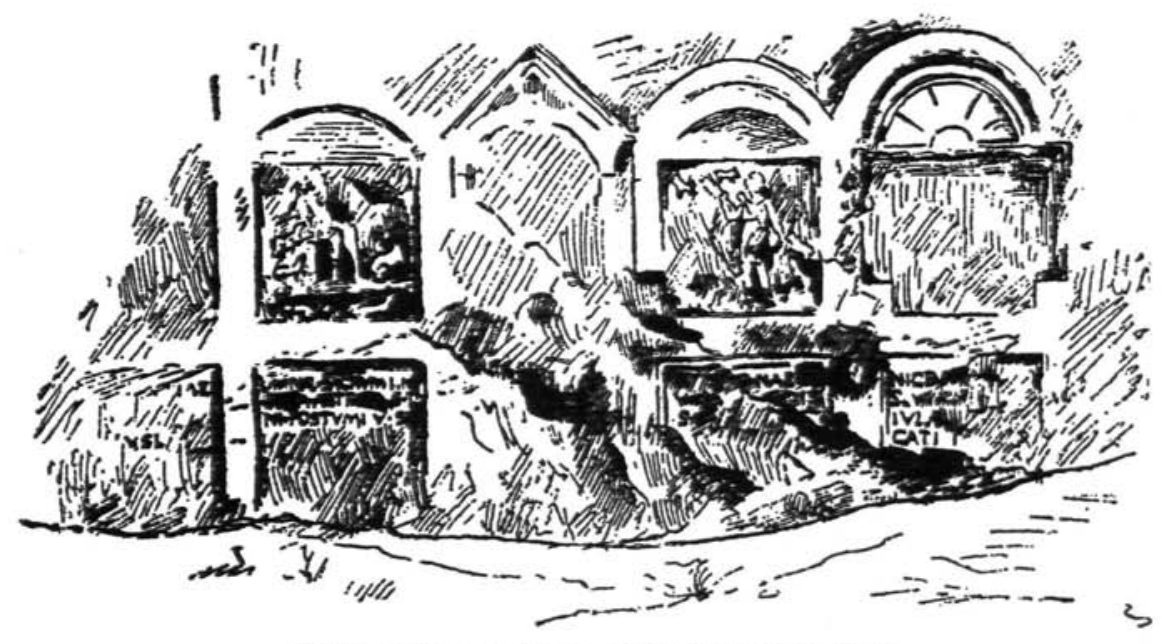

SACELLUM dedicado a Diana, seguin dibujo tomado del natural.

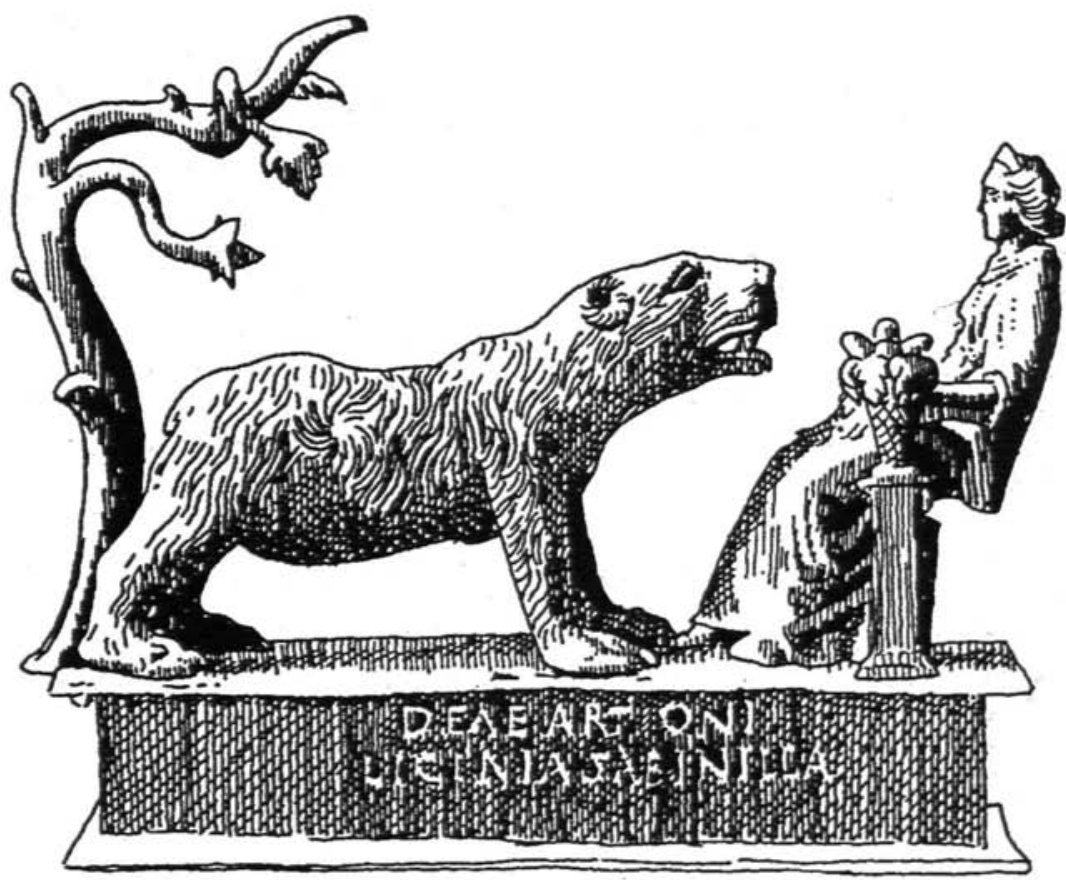

b)

Lámina 5. a) El santuario de Diana de Segóbriga, según dibujo de P. Quintero Atauri, 1913. b) Grupo en bronce de la diosa Artio y el oso. Museo Histórico de Berna (Suiza), según P. Jenkins, en M. J. Green, 1989, fig. 10 


\section{BIBLIOGRAFÍA}

AlBerTINI 1923: E. Albertini, Les divisions administratives de l'Espagne romaine, París.

ALFÖLDY 1985: G. Alfödy, "Epigraphica Hispanica. VI. Das Diana-Heiligtum von Segobriga", ZPE 58, 139 ss. fig. 5 y láms. VII-X.

- 1991: id., "Epigraphica Hispanica. XI: Ein römisches Grabdenkmal aus Malamoneda (Hontanar, Toledo)", ZPE 86, 117-119 con láms. III b y c.

- 1995: id., "Inscripciones, sacrificios y misterios: El santuario rupestre de Panóias/Portugal. Informe preliminar", $M M$ 36, 252-258 (bibl. en nn. 2 y 3).

Almagro 1976: M. Almagro Basch, "El "delubro" o sacellum de Diana en Segóbriga, Saelices (Cuenca)", RABM 79.1, $187 \mathrm{ss.}$

- 1983: id., Segobriga I (EAE 123), Madrid.

- 1984: id., Segobriga II. La epigrafia, Madrid.

Álvarez-SANChís 1993: J. R. Álvarez-Sanchís, "En busca del verraco perdido", Complutum 4, 153-168.

BOUCHER 1976: S. Boucher, Recherches sur les bronzes figurés de Gaule pré-romaine et romaine (École Française de Rome), París-Roma (que no he podido consultar).

BRAUN 1909: F. Braun, Die Entwicklung der spanischen Provinzialgrenzen in römischer Zeit, Berlín.

CAnto 1996: A. M. ${ }^{a}$ Canto, Epigrafía Romana de la Beturia Céltica, Madrid, U.A.M., e.p.

CARrera 1994: E. de la Carrera Hontana, -La hoja K-30 de la Tabula Imperii Romani y Madrid-, Estudios de Prehistoria y Arqueología Madrileñas 9, 155-157.

CORNIDE 1799: J. Cornide, "Noticia de las antigüedades de Cabeza del Griego", Memorias de la Real Academia de la Historia III, 72 ss.

CIL II: Corpus Inscriptionum Latinarum. II. Hispaniae.

GORGES 1992: J.-G. Gorges, "Archéologie et économie des campagnes hispano-romaines: Vingt cinq ans de bibliographie commentée (1968-1992)", MCV 28, 1.

GREEN 1989: M. J. Green, Symbol and Image in Celtic Religious Art, Londres-Nueva York.

HERNANDO 1995: M. ${ }^{a}$ R. Hernando Sobrino, "La integración del territorio oriental de los vettones en el marco administrativo provincial romano", Hispania Antiqua XIX, $77-93$.

KNAPp 1992: R. C. Knapp, Latin Inscriptions of Central Spain, Berkeley. 
Mangas, J. et al. 1988: J. Mangas, S. Ripoll, J.J. Storch de Gracia, "Piedra Escrita, interesante monumento de época romana, Revista de Arqueologia 85, 58-59.

MERMET 1993: Chr. Mermet, "Le sanctuaire gallo-romain de Châteauneuf (Savoie)", Gallia 50, 95-138.

MORÓN-MARTín 1995: J. L. Morón y J. L. Martín Mompeán, "Piedra Escrita" (Cenicientos, Madrid), Revista del Colegio Oficial de Doctores y Licenciados (sección Apuntes de Arqueologia), n. ${ }^{\circ}$ 69, noviembre, 20-22.

Pena 1982: M. ${ }^{2}$ J. Pena, "Contribución al estudio del culto de Diana en Hispania", La religión romana en Hispania (coloquio Madrid 1981). Madrid, 47 ss.

QUINTERO 1913: P. Quintero Atauri, Uclés. Excavaciones efectuadas en distintas épocas y noticias de algunas antigüedades ( $2 .^{2}$ parte), Cádiz.

RE: Pauly-Wissowa-Kroll, Realencyclopädie für Altertumswissenschaft, t. IX, 1903.

RIVAS 1993: J. C. Rivas Fernández, "Recensión de la Tabula Imperii Romani", Boletín Auriense 23.

SOLIN-SALOMIES 1988: H. Solin y O. Salomies, Repertorium nominum gentilium et cognominum Latinorum, Hildesheim-Zurich-Nueva York.

TIR, 1993: VV.AA., Tabula Imperii Romani. Hoja K-30: Madrid, Caesaraugusta, Clunia (Unión Académica Internacional, Comité Español), Madrid.

Tovar 1989: A. Tovar, Iberische Landeskunde.2.III.Tarraconensis, Baden-Baden.

VÁzquez 1982a: A. M. ${ }^{a}$ Vázquez y Hoys, “Consideraciones estadísticas sobre la religión romana en Hispania", La religión romana en Hispania (coloquio 1981), Madrid, 165 ss.

- 1982b: ead., La religión romana en Hispania: Fuentes epigráficas, arqueológicas y numismáticas (tesis doctoral, 1974), Madrid.

Post scriptum..- J. Mangas, J. Carrobles y S. Rodriguez, publicaron en 1992 ("Deana y mulieres. Nueta inscripción de la protincia de Toledo", Gerión 10, 243-258, cf. HEp. 4. 1994, 885) un interesante epigrafe procedente de Gálvez (TO.), excelente paralelo para Cenicientos como dedicación a Diana en su faceta de protectora de las mujeres. Las dedicantes se denominan mulieres Albol---J (lín. 2-3), origónimo que quizá se pudiera relacionar, según los autores, con la Albura/Lebura que debía encontrarse entre Toledo y Talavera. El yacimiento está en el valle del río Alpuébrega, hidrónimo que parece conservar bien una antigua y céltica Alpobriga. 